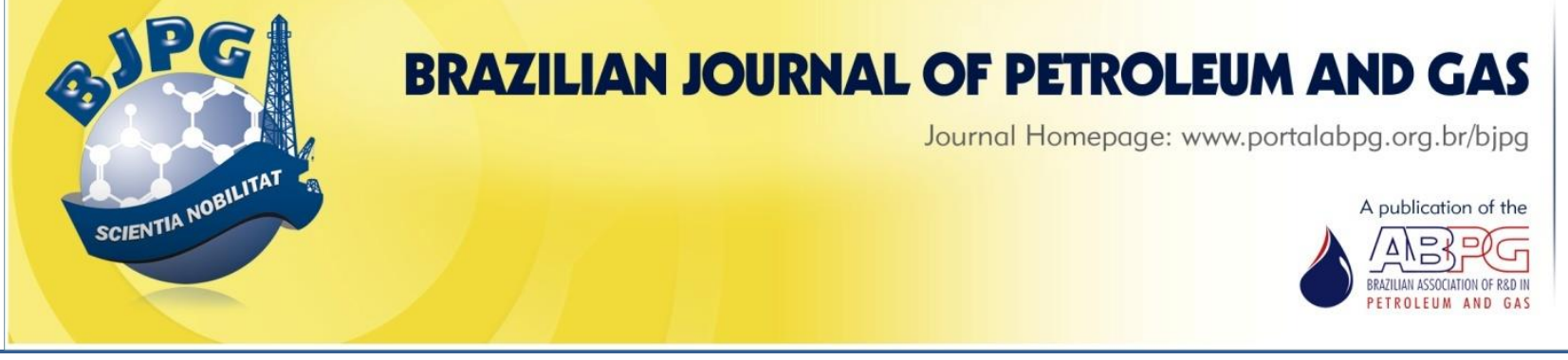

\title{
RHEOLOGICAL AND THERMAL BEHAVIOR OF WEATHERING-AGED POLYMER MODIFIED BITUMEN
}

\author{
${ }^{a}$ Sá Araujo, M. F. A.; ${ }^{b}$ Leite, L. F. M.; ${ }^{\text {P Pasa, V. M. D.; }}{ }^{\text {Lins, V. F. C. }}{ }^{1}$ \\ ${ }^{a}$ Highway Department of Minas Gerais, MG, Brazil \\ ${ }^{\mathrm{b}}$ Cenpes/Petrobrás, Leopoldo Américo Miguez de Mello Research and Development Center, RJ, Brazil \\ ${ }^{c}$ Chemistry Departament,Federal University of Minas Gerais, MG, Brazil \\ ${ }^{d}$ Corrosion and Surface Laboratory, Federal University of Minas Gerais, MG, Brazil
}

\begin{abstract}
This paper evaluates the effect of weathering degradation on styrene-butadiene-styrene modified bitumen and conventional bitumen using a dynamic shear rheometer and thermal analysis. The aging was done in two steps: samples of asphalt binder were aged for a short term in the rolling thin film oven for 85 minutes. The long term aging was done in a weathering chamber at the determined temperature with UV rays acting on the thin film surface of binder (after RTFOT aging) covering rock plates for different exposure times. At low frequencies, the complex modulus of asphalt binders with and without polymer additions increased as the exposure time in the weathering chamber increased. Before aging, the complex modulus of polymer modified bitumen was higher than the complex modulus of conventional asphalt binder at low frequencies. For 50h aging, SBS modified bitumen showed a lower complex modulus at low frequencies than the conventional bitumen. For $100 \mathrm{~h}$ aging, the benefit of polymer addition was minimized, and values of complex modulus of both binders were close. Thermal analysis showed a marked drop in thermal stability of aged samples after 100 hours for the polymer modified bitumen and after 50 hours for the conventional bitumen.
\end{abstract}

\section{KEYWORDS}

weathering test; photodegradation; modified bitumen; rheology; thermal analysis

\footnotetext{
${ }^{1}$ To whom all correspondence should be addressed.

Address: Department of Chemical Engineering, Corrosion and Surface Laboratory, Federal University of Minas Gerais, 6627 Antonio Carlos Avenue, Belo Horizonte-MG, Brazil.

CEP: 31270-090 | Telephone/Fax number: +55 31 34091775/ +55 31 34091789|e-mail: vlins@deq.ufmg.br doi:10.5419/bjpg2013-0013
} 


\section{INTRODUCTION}

Bitumen aging is one of the main factors causing the degradation of asphalt pavement. In bitumen aging, two mechanisms are involved: chemical changes in the binder (irreversible) and physical hardening (reversible). The first one involves the oxidation process (Mouillet et al., 2008; Lins et al., 2008), volatile components loss from bitumen. The second may be attributed to molecular reorganization to approach an optimum thermodynamic state under a specific set of conditions (Tabatabaee et al., 2012).

Oxidative aging causes hardening of bitumen and consequently deterioration of asphalt pavements. One of the main causes of bitumen aging and hardening in service is the atmospheric oxidation of molecules with the formation of highly polar and strongly interacting functional groups containing oxygen and sulfur.

In pavements, bitumen is exposed to the aging processes during storing, mixing, transporting, and laying, as well as during its service life. Field aging is a combination of oxygen pressure by the tires, ultraviolet rays from the sun, moisture from the rain, and snow melting.

The use of Polymer modified asphalt (PMA) increased in recent years, for the construction of pavements, primarily due to its ability to stiffen the binder at high temperatures without stiffening it at low temperatures, resulting in reduced permanent deformation without harming thermal cracking and fatigue life (Topal, 2010; Bernier et al., 2012; Zhang \& Hu, 2013; Iskender et al., 2012; Sengul, 2013; Modarres, 2013). Given the low polymercontent usually found in the paving industry, the morphology is usually composed of maltenes polymer-rich phase (MPRP) dispersed within an ARP (asphaltene-rich phase) matrix. In addition, literature shows that polymer modifiers, in some cases, are able to decrease the deleterious impact of binder oxidative aging and thereby resulting in more durable pavements (Ruan et al, 2003).

The properties of PMA depend upon the characteristics and content of the polymer, the base asphalt binder source, and the preparation blending process (Giuliani et al., 2009). Typically, for the modification of asphalt binders, two kinds of polymeric additives, elastomers and plastomers, are used. The styrene block copolymer, which is a termed thermoplastic rubber or elastomer, has proved to have the greatest potential when blended with an asphalt binder. Therefore, the modification of asphalt binders using rubber and styrene-butadiene-styrene (SBS) has been widely studied (Yildirim, 2007; Sugano et al., 2011; Iskender et al., 2012; Alvarez et al., 2012; Presti, 2013). The mechanism associated with SBS polymer modification consists of a swelling of the polymer through the absorption of the light aromatic fractions of the base bitumen and the establishing of a rubber-elastic network within the modified binder (Airey, 2003).

Several studies indicate that the oxidation of SBS modified asphalt result in an increase of asphaltenes in base binders, and size-exclusion chromatography indicates that polymeric modifiers degrade to a lower molecular size (Ruan et al., 2003).

Rheology is one of the most useful tools for the study of polymer modified asphalt. Polymer modification of asphalt binders for pavement provides increased viscosity at high pavement temperatures, leading to a better rutting resistance. It also provides a higher ductility at low temperatures, which prevents cracking. Both effects produce a higher life time of pavements. The polymer addition results in a significant decrease in phase angle, $\delta$, especially over the range of intermediate to low frequencies, improving the elasticity of the binder (Pérez-Lepe et al, 2003).

Although the polymer addition increases both the storage and loss moduli of asphalt, the polymer is more effective in increasing storage modulus. As a result, this unequal rate of increase results in an overall decrease in phase angle. In addition, a plateau region is formed in the loss tangent master curves for modified binders over the intermediate frequency that can be attributed to the possible formation of a polymer network (Ruan et al., 2003).

The present paper evaluates the weathering aging properties of a linear styrene-butadienestyrene (SBS) modified bitumen and conventional asphalt cement by using dynamic shear and thermal analysis. A linear styrene-butadienestyrene was used, but literature (Mouillet et al., 2008) reported that the architecture of elastomers (linear or radial) does not affect their aging by UV 
radiation in a bituminous matrix. The materials in the aging test were exposed to alternating cycles of xenon radiation and moisture at controlled temperatures, for 50,100, 150, and 200 hours. The effect of weathering aging on rheological and thermal properties of polymer modified bitumen (PMB) is not found in the literature. The aging process of PMB is usually performed using Rolling Thin Film Oven Test (RTFOT) and Pressure Aging Vessel (PAV) (Mastrofini \& Scarsella, 2000; Lesueur, 2009). There are a few papers in literature studying the standard simulated aging process (RTFOT + PAV) or the not conventional aging process (RTFOT + UV exposure in a weathering oven) that correspond to hot mix plus road service (Durrieu et al., 2007).

\section{MATERIALS AND METHODS}

The samples of asphalt binders studied were a conventional asphalt cement 50/70 penetration (B samples) and a styrenebutadiene-styrene (SBS) modified bitumen with $3.6 w t \%$ of a linear styrene/butadiene/styrene - SBS (F samples), in a base of asphalt cement 50/70 penetration. The SBS TR1101M polymer showed $30 \%$ styrene content, and $155400 \mathrm{~g} / \mathrm{mol}$ molecular weight. The polymer modified bitumen (PMB) showed $0.7 \%$ of carbonyl and $5.9 \%$ of sulfoxide. The PMB samples were obtained after 2 $\mathrm{h}$ of high shear stirring (5000 rpm) using Silverson L4RT under normal air pressure, at $180^{\circ} \mathrm{C}$ for the bitumen modified with unsatured elastomer (SBS).

Plates of granite were made by cutting aggregates. The plates were painted with a layer of $0.6 \mathrm{~mm}$ binder thickness to simulate the binder thickness on the aggregate surface (AFNOR, NF THAT IN 11 341) in an asphalt mixture. The aging was done in two steps. At first, the hot mix aging was simulated by RTFO, and then the second step road service was simulated by exposing the asphalt binders to alternating cycles of radiation and moisture at a controlled temperature of $60^{\circ} \mathrm{C}$. The effect of sunlight was obtained with a xenon arc lamp. The xenon radiation is the closest to sunlight, as it includes ultraviolet, visible light and infrared radiation. The dew point and rain were simulated with moisture condensation and spraying of water. The conditions of exposition in the weathering chamber were according to the ASTM method D4798. The cycles lasted 80 minutes: 64 minutes of xenon radiation and 16 minutes of radiation and water spray at a temperature of $60^{\circ} \mathrm{C}$, and irradiation at $340 \mathrm{~nm}=0.35 \mathrm{~W} / \mathrm{m}^{2}$. The variable power 3500-6500W was used to maintain the intensity of irradiation. The samples were for different exposition times: 50, 100, 150, and 200 hours.

Dynamic shear properties were measured with a Malvern Gemini dynamic shear rheometer in a parallel plate configuration. For temperatures from $5^{\circ} \mathrm{C}$ to $35^{\circ} \mathrm{C}, 8 \mathrm{~mm}$ diameter stainless steel plates were used with a gap of $2 \mathrm{~mm}$. At higher temperatures $\left(40^{\circ} \mathrm{C}\right.$ to $\left.65^{\circ} \mathrm{C}\right), 25 \mathrm{~mm}$ plates were used to provide more sensitivity to the softer material and also to reduce thermal gradients in the sample across the gap of $1 \mathrm{~mm}$. Measurements were conducted at temperatures from $5^{\circ} \mathrm{C}$ to $65^{\circ} \mathrm{C}$ by using a frequency sweep from $0.01 \mathrm{~Hz}$ to $25 \mathrm{~Hz}$ in order to obtain isotherms. The data obtained with these isotherms provided the information needed to plot the Black space that relates phase angle and complex modulus. Using the time-temperature superposition principle (TTSP), these frequency curves (isotherms) determined at different temperatures were shifted, each one according to its individual shift factor to plot the traditional master curve at the reference temperature of $25^{\circ} \mathrm{C}$ which is a graphical representation of the variation of the absolute value of the complex modulus $\left|G^{*}\right|$ with the frequency (Guedes, 2011).

Thermal analysis (Thermogravimetry -TG, Differential Thermogravimetry - DTG, Differential Thermal Analysis -DTA) were performed by using Shimatzu DTG 60 equipment, nitrogen atmosphere, heating rate of $10^{\circ} \mathrm{C} /$ minute, and temperature ranged from room temperature up to $750^{\circ} \mathrm{C}$.

\section{THEORY}

Aging is a very complex process in traditional bitumen and it becomes more complex when a polymer is added, because thermal degradation of the polymer may occur. The polymer fragments formed may contribute to change physicochemical characteristics of asphalt such as penetration, softening point, viscosity, and rheological 
parameters (Leite et al., 2010).

Penetration and ring and ball tests proved to be sufficient for specification purposes until the development of modern polymer modified asphalts. With the advent of newer asphalt types, it became necessary the use of other tests that could measure important features of bitumen rheology such as the susceptibility to loading stress, loading time, and temperature.

Rheology has led to a better knowledge of bitumen behavior that occurs when subjected to different thermal and mechanical conditions, as seen during road construction and service in the field (Mastrofini \& Scarsella, 2000). The development of the early colloidal model of bitumen was based on rheological observations (Lesueur, 2009).

A general agreement was found on the marked non-Newtonian behavior at room temperature of bitumen in the 50 's, as a consequence of the gel structure in the materials (Saal, 1950). Later, it would account for the presence of delayed elasticity and some non-linearity in all bitumen materials (Anderson et al., 1994). At low temperatures (below $20^{\circ} \mathrm{C}$ ), the shear modulus reaches a constant value of order of $1 \mathrm{GPa}$, independent of temperature and frequency corresponding to the glassy state (Lesueur, 2009). This value is typical of amorphous organic materials such as some polymers (Ferry, 1980). In parallel, the phase angle diminishes down to $0^{\circ}$.

Asphalt exhibits Newtonian, non-Newtonian, and viscoelastic behavior with temperature variation. The transition temperature varies with the processing methods and aging conditions (Rekha \& Krishnan, 2011). At high temperatures bitumen is a viscous Newtonian liquid characterized by a temperature-dependent viscosity, $\eta_{0}(\mathrm{~T})$, related to the complex modulus $\left|G^{*}\right|$, and the testing frequency, $t\left(\mathrm{rad} . \mathrm{s}^{-1}\right)$ by:

$\eta_{0(\mathrm{~T})}=\left|\mathrm{G}^{*}\right| . \mathrm{t}$

At high pavement temperatures the phase angle increases to $90^{\circ}$. Between these two asymptotic behaviors, the mechanical response of bitumen is an intermediate state between an elastic solid and a viscous liquid, a viscous-elastic material (Polacco et al., 2006).

\section{RESULTS AND DISCUSSION}

The weathering-aged asphalt binder samples with and without polymer modifiers were analyzed by using thermal and rheological analysis.

\subsection{Rheological analysis}

At low frequencies, the SBS modified bitumen had a higher complex modulus, $\left|G^{*}\right|$, than the conventional asphalt cement before aging where the SBS polymer network is particularly dominant. At high frequencies (or low temperatures) both asphalt binders have the tendency to equalize the modulus (Figure 1). The higher value of the complex modulus found for the PMB sample happens because of an increment of both the viscous ( $\left.G^{\prime \prime}\right)$ and elastic ( $\left.G^{\prime}\right)$ component. The reason is that the 3-dimensional structure of SBS mainly contributes to the deformation resistance of bitumen at low frequency range. These characteristics indicate a good resistance of the binder to high-temperature permanent deformation and probably low-temperature cracking (Liu et al., 2013). It means that the virgin SBS modified bitumen is more resistant to a shortterm permanent deformation (rutting resistance) than the conventional asphalt cement.

The samples aged for 150 and 200 hours had a high brittleness and the rheological results obtained by DSR (Dynamic shear results) were not decisive. The aged material could not adhere well to the plates causing wrong strain and stress values. These results will not be considered in the present study.

At low frequencies (from $10^{-6}$ up $10^{2} \mathrm{rad}$ ), and for aging time up to 100 hours, the complex modulus of asphalt binders, with and without polymer additions, increased as the exposure time in the weathering chamber increased. In the aging test, cycles of xenon radiation, moisture and temperature could promote cross linking in samples of asphalt binder with and without polymer modifier. Polacco et al. (2004) reported that even if it is not possible to determine the exact nature of the chemical interactions between asphalt and polymer, master curves obtained from dynamic data clearly show that, during the cure at high temperatures, the polymer modified asphalt tends to have the behavior of a cross-linked network. Figure 2 shows the results for the 


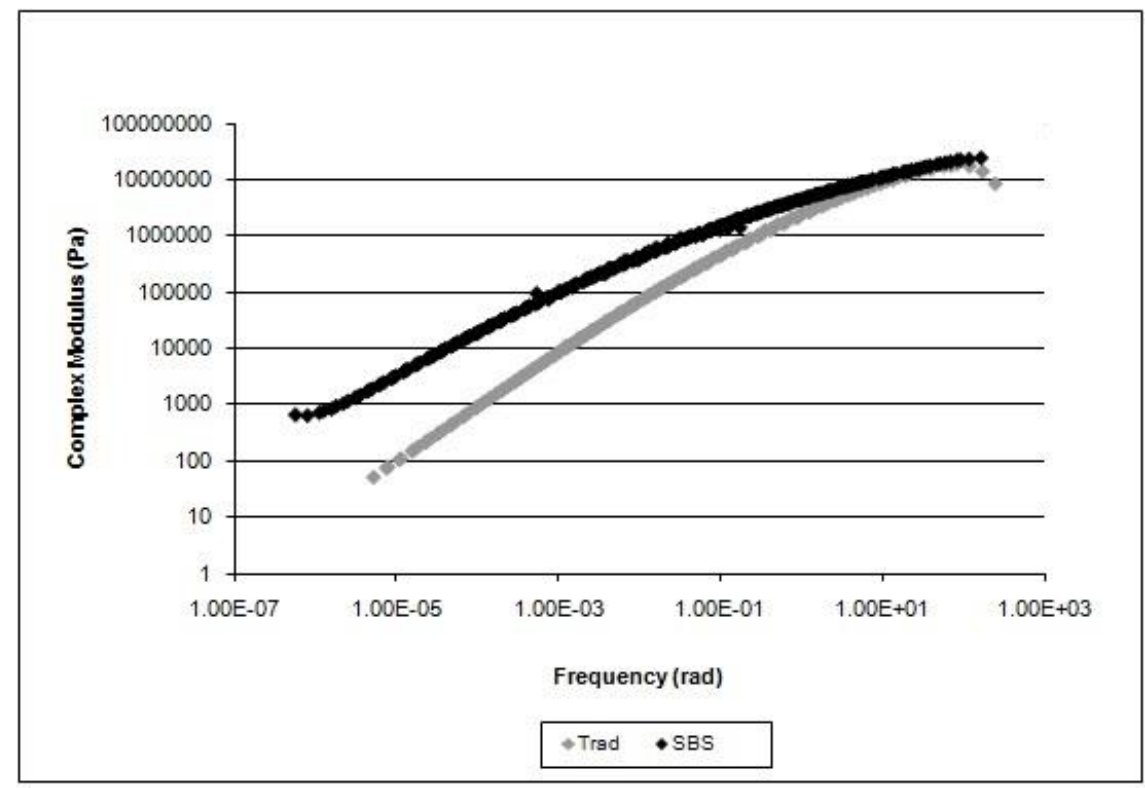

Figure 1. Absolute value of complex modulus versus frequency curves for polymer modified bitumen (F) and conventional asphalt binder (B) before aging testing. The reference temperature for the master curve is $25^{\circ} \mathrm{C}$.

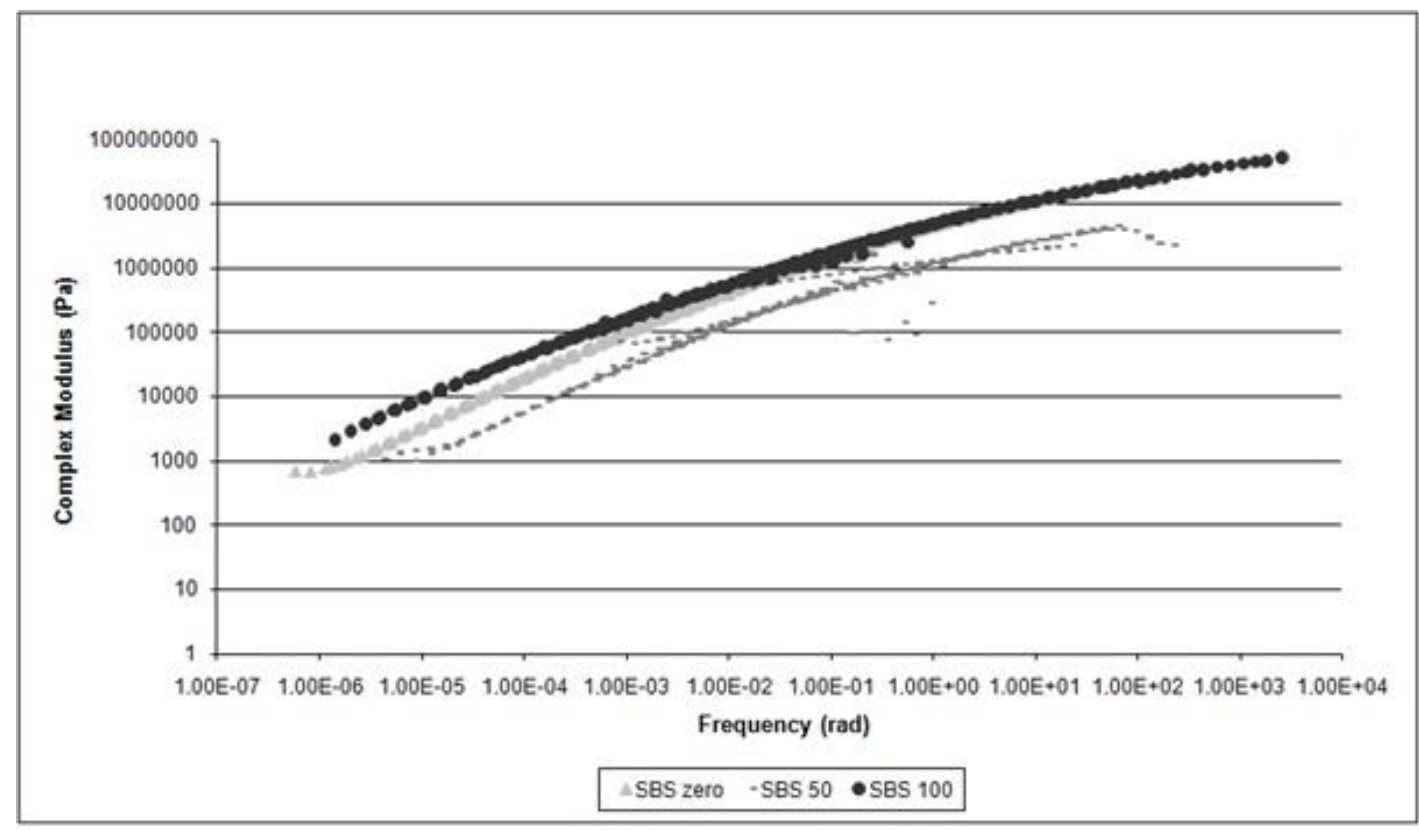

Figure 2. Absolute value of complex modulus versus frequency curves for polymer modified bitumen (F) before aging testing ( $F 0)$ and after 50 and 100 hours of aging ( $F 50$ and $F 100$ ). The reference temperature for the master curve is $25^{\circ} \mathrm{C}$.

styrene-butadiene-styrene modified bitumen. Ruan et al. (2003) and Lesueur (2009) reported the decrease of aromatic content in the aged samples due to the production of resins and asphaltenes from the aromatic groups. The increase of asphaltene fraction can also increase the complex modulus for the samples aged for 100 hours. The SBS modified bitumen aged for 50 hours (Figure 2) showed a lower complex modulus than the virgin SBS modified bitumen, decreasing its benefit related to rutting resistance. The behavior obtained for the SBS modified binders aged for $50 \mathrm{~h}$ 


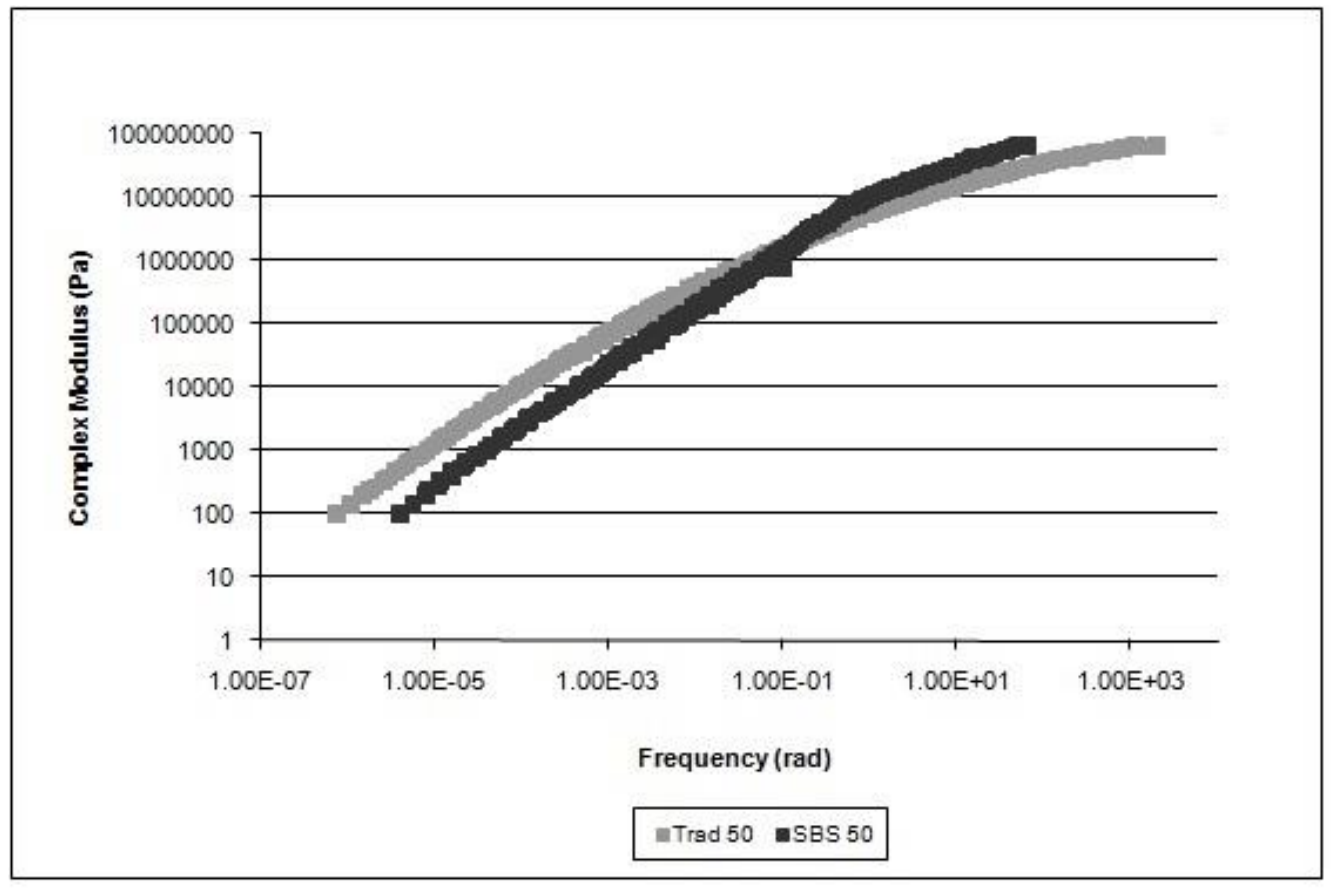

Figure 3. Absolute value of complex modulus versus frequency curves for polymer modified bitumen (F) and conventional asphalt binder (B) after 50 hours of aging testing. The reference temperature for the master curve is $25^{\circ} \mathrm{C}$.

can be explained by the fact that part of the butadiene double bonds of SBS polymer broken with the aging, reducing its molecular weight. For samples aged for $100 \mathrm{~h}$, the SBS modified bitumen showed a higher complex modulus than the virgin SBS asphalt binder at low frequencies, as expected. This behavior can be explained by the hardening of the bitumen base of SBS modified bitumen plus no more scissions in polymer molecules that occurred with exposure time of 50 hours.

For samples aged for 50h (Figure 3), the SBS modified bitumen showed a lower complex modulus at low frequencies than the conventional asphalt binder, decreasing its benefit related to rutting resistance. The behavior obtained for the SBS modified binders aged for $50 \mathrm{~h}$ can be explained by the fact that part of the butadiene double bonds of SBS polymer broke with the aging, reducing its molecular weight and lowering the modulus whereas the asphalt cement hardened in a higher degree with the aging process.

For samples aged for 100h (Figure 4), the SBS modified bitumen showed a higher complex modulus than the conventional asphalt binder at low frequencies, as expected. This behavior can be explained by the hardening of the bitumen base of
SBS modified bitumen plus no more scissions in polymer molecules with exposure time of 50 hours. However, the benefit of polymer addition in bitumen was minimized after 100 hours of aging testing.

Compared to their base bitumen, modified asphalt binders with polymer addition showed a marked increase in the complex modulus at low angular frequencies, demonstrating higher rutting resistance (Figure 1). Comparing phase angle behavior, it was observed that the addition of polymer in asphalt binders, without aging, produced a clear decrease in phase angle (Ruan et al., 2003; Airey, 2003), meaning elasticity increase due of the rubber addition (Figure 5). Measurements of $\delta$ are generally considered to be more sensitive to the chemical structure and, therefore, to the modification of bitumen than the ones of complex modulus.

For the conventional asphalt cement, the aging process decreased the phase angle for aging up to 100 hours (Figure 6). This result can be explained considering that the asphaltene content produced after 100 hours of aging was not sufficient to promote an increase in the brittleness of asphalt binder. Fernández-Goméz et al. (2014) reported 


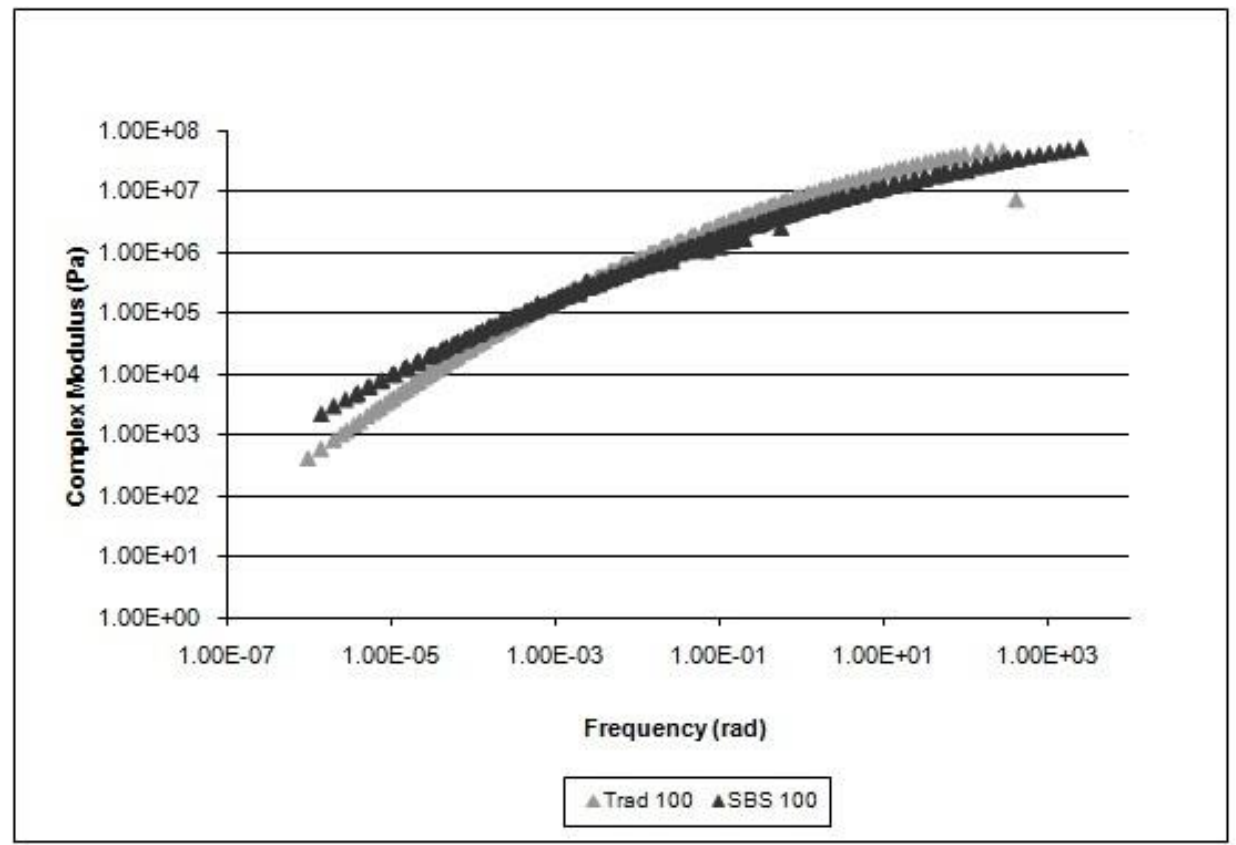

Figure 4. Absolute value of complex modulus versus frequency curves for polymer modified bitumen (F) and conventional asphalt binder (B) after 100 hours of aging testing. The reference temperature for the master curve is $25^{\circ} \mathrm{C}$.

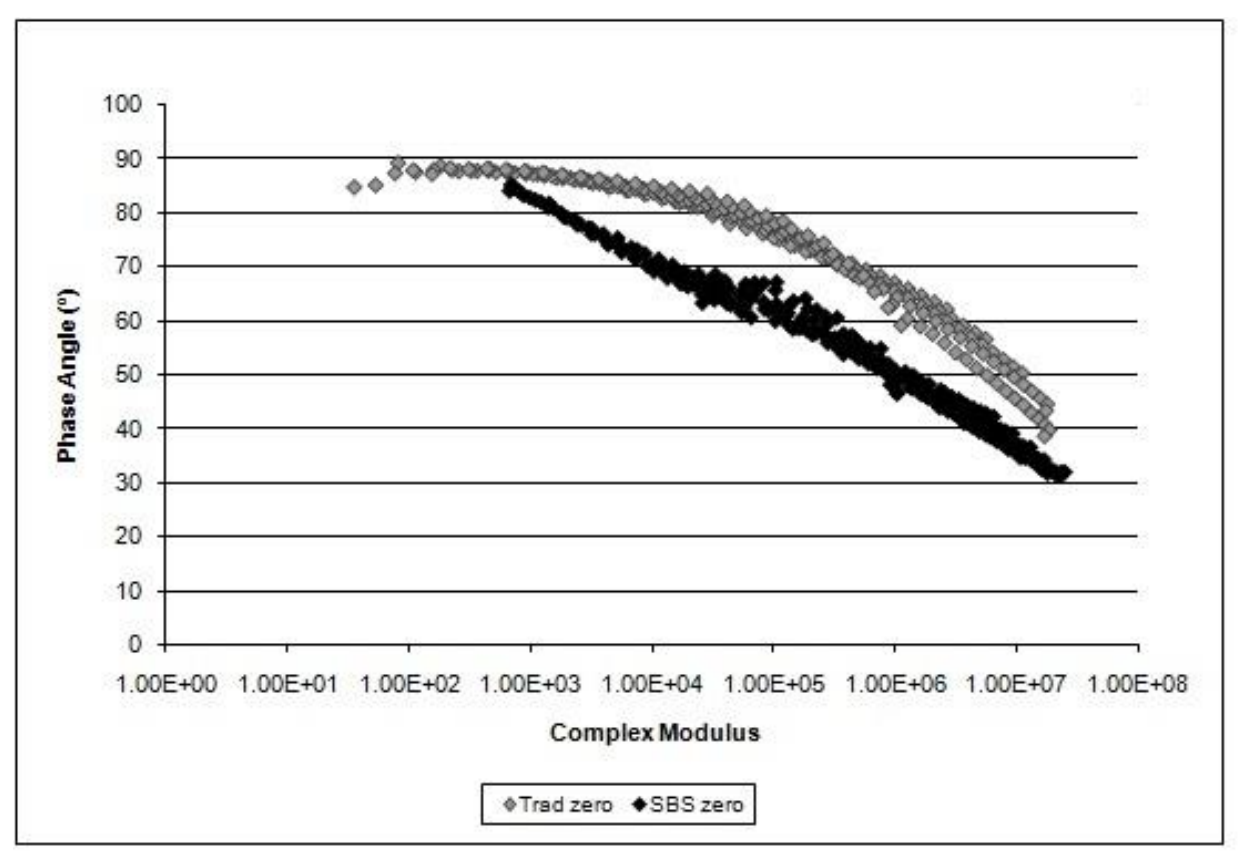

Figure 5. Phase angle versus absolute value of complex modulus curves for polymer modified bitumen (F) and conventional asphalt binder (B) before aging testing.

that chemical testing demonstrates that during short-term aging, saturates and naphthene aromatics convert into resins-the result of oxidation-until productions of these resins stops. Then, during the long-term aging resins are converted into asphaltenes. Fernández-Goméz et al. (2014) studied asphalt aging using the Rolling Thin Film Oven (RTFO) test and the Pressure Aging Vessel (PAV), as well as an ultraviolet (UV) chamber. They reported that long-term aging produced by the PAV was similar to that of the RTFO treatment with an additional $500 \mathrm{~h}$ of UV 


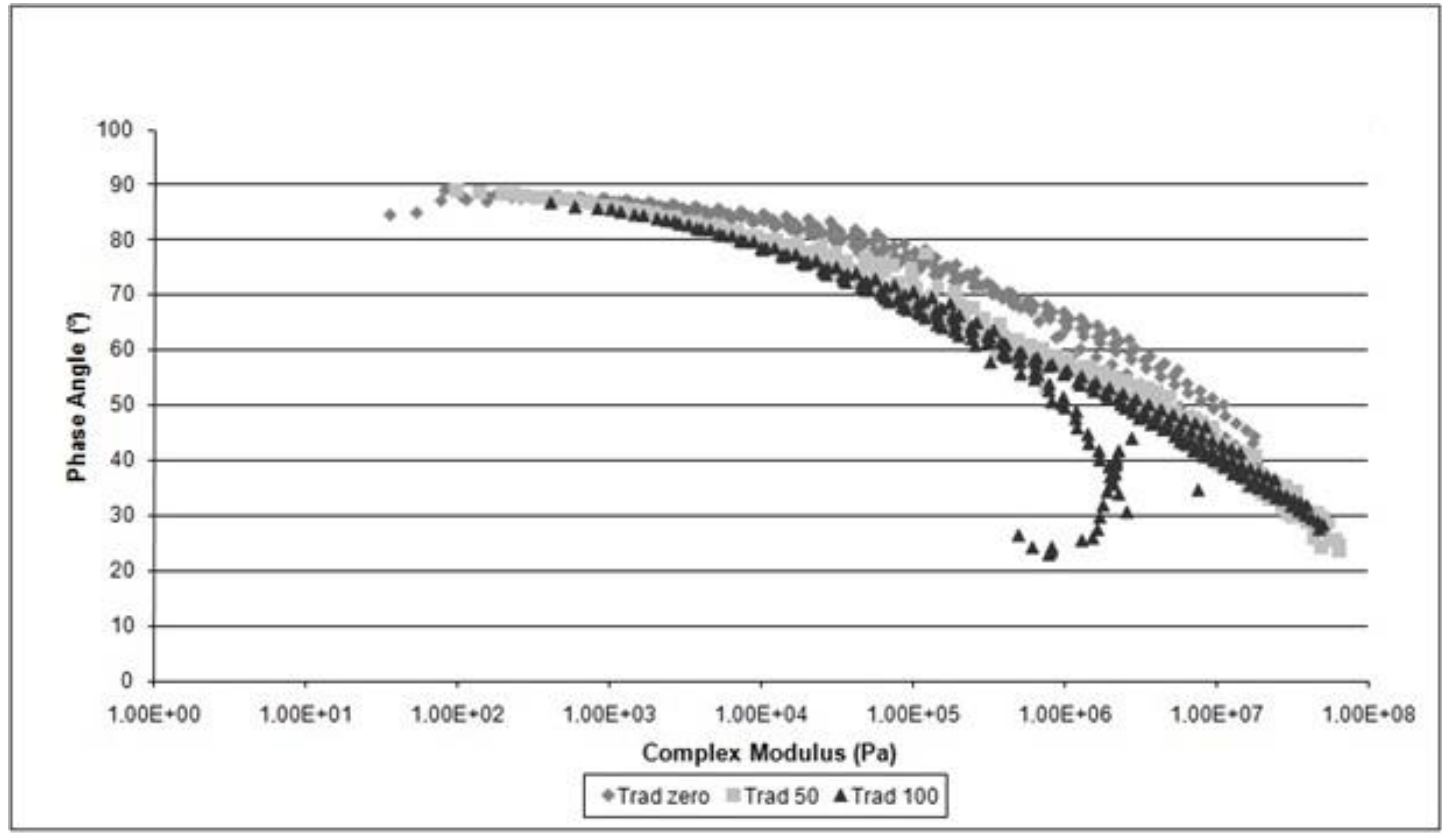

Figure 6. Phase angle versus absolute value of complex modulus curves for conventional asphalt binder (B) before aging testing (B 0), and after 50 (B 50) and 100 hours of aging (B 100).

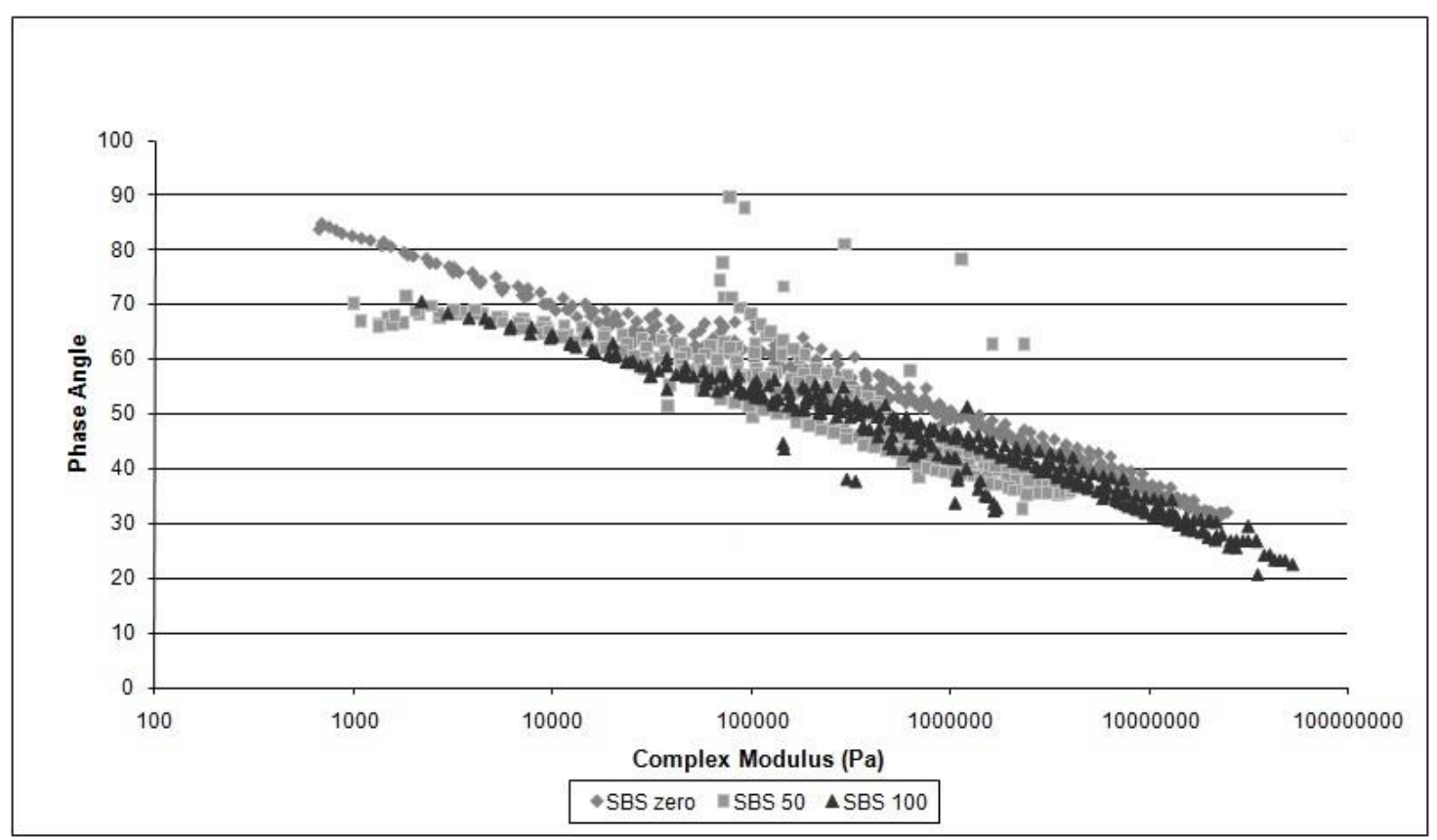

Figure 7. Phase angle versus absolute value of complex modulus curves for polymer bitumen (F) before aging testing ( $F 0)$ and after 50 (F 50) and 100 hours of aging ( $F 100)$.

radiation. Rebelo et al. (2014) reported that the aging process induces a growth and nucleation of the asphaltene micelles with a concomitant reduction of the maltene phase, whereas the short term aging induces the formation of fractal-like micellar structures. The fragmented structure of asphalt binder became more resistant to permanent deformation and more susceptible to elastic deformation.

For the polymer modified bitumen, the phase angle also decreased as the exposure time increased as shown in Figure 7. There is a region in the curve of phase angle versus complex modulus 
from $70^{\circ}$ to $50^{\circ}$, where the lowest values of phase angles were observed for the samples aged for 100 hours. In some regions from $50^{\circ}$ to $30^{\circ}$, the SBS bitumen aged for 50 hours showed the lowest phase angle. The nucleation of the asphaltene micelles with a concomitant reduction of the maltene phase contributed to increases in the elasticity of the polymer asphalt binder (Rebelo et al., 2014).

\subsection{Thermal Analysis}

The mass loss of asphalt binder starts at a higher temperature than the mass loss of polymer modified asphalt, but the mass loss of the asphalt binder was higher than the polymer binder (Figure 8).

All samples of conventional asphalt cement and SBS modified bitumen showed one decomposition stage of $85 \mathrm{wt} \%$, at $300^{\circ} \mathrm{C}$, related to the organic compounds. Benbouzid \& Hafsi (2008) reported that the thermal degradation of bitumen is a one stage process for pure bitumen and a two stage process for oxidized bitumen. However, the thermal behavior of bitumen depends on several variables such as the heating rate, temperature range used, the chemical composition and physical properties of bitumen, polymer addition, and oxidation process of bitumen.
Among the conventional asphalt cement samples, the sample without aging showed the highest thermal stability (Figure 9). The thermal stability decreased as the exposure time increased. The thermal stability of samples aged for 100, 150, and 200 hours was similar. The loss of thermal stability after 50 hours of aging indicated that a chemical change in the material structure occurred after 50 hours of exposure in the weathering chamber. After 50 hours of exposure in the weathering chamber, a molecular cracking and a loss of volatile compounds at lower temperatures occurred. The asphalt cement sample aged for 50 hours showed the highest residue content, $18 \mathrm{wt} \%$, at $750^{\circ} \mathrm{C}$. The other samples showed a content of residue of $10 \mathrm{wt} \%$.

For the styrene-butadiene-styrene modified asphalt binder, the samples showed one decomposition stage of $85 \mathrm{wt} \%$ at $300^{\circ} \mathrm{C}$, associated to the organic compounds (Figure 10). The samples aged for 100 hours showed the highest thermal stability and the highest residue content $(20 \%)$, at $750^{\circ} \mathrm{C}$, associated to the inorganic compounds. Samples of the polymer binder without aging and ones aged for 50,150 , and 200 hours had a similar thermal behavior. The lowest thermal stability was found for the polymer binder without aging.

A marked drop in thermal stability of aged

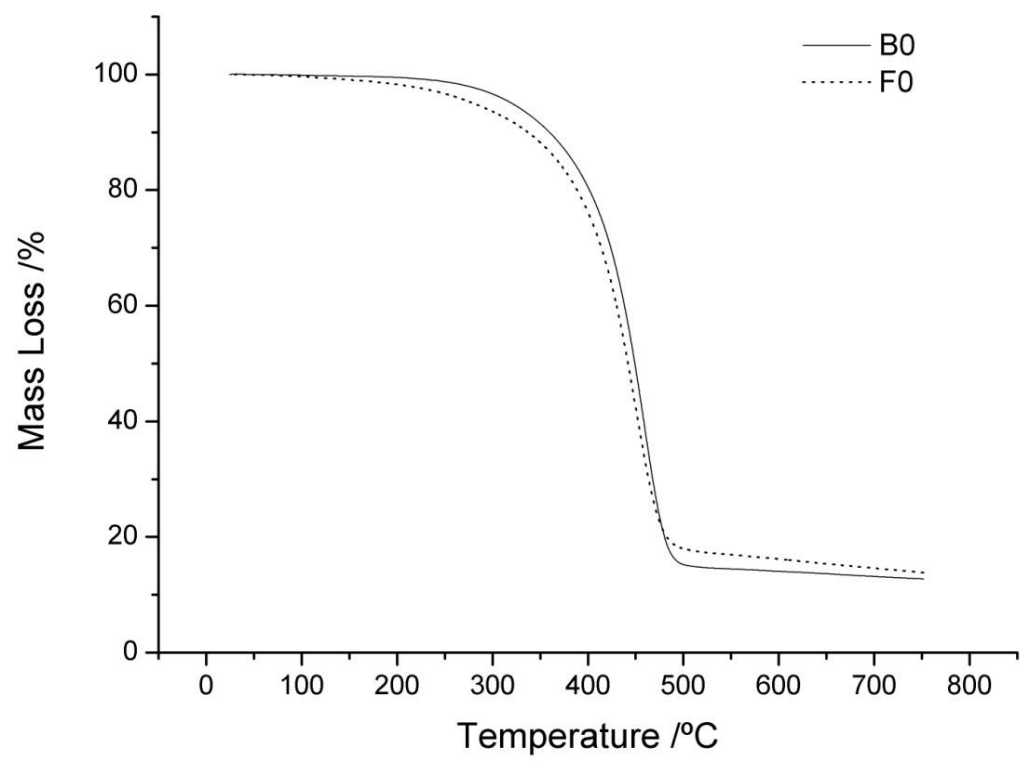

Figure 8. TG curves for asphalt binder (B) and polymer modified binder (F) before aging process. 
samples was observed after 100 hours for the polymer modified bitumen and after 50 hours for the conventional bitumen.

Differential Thermogravimetry (DTG) results confirmed the presence of one decomposition stage. The maximum mass loss rate was at $450^{\circ} \mathrm{C}$ for all samples (asphalt cement and SBS modified asphalt binder).

For the polymer-modified bitumen, the highest mass loss rate was observed for the samples

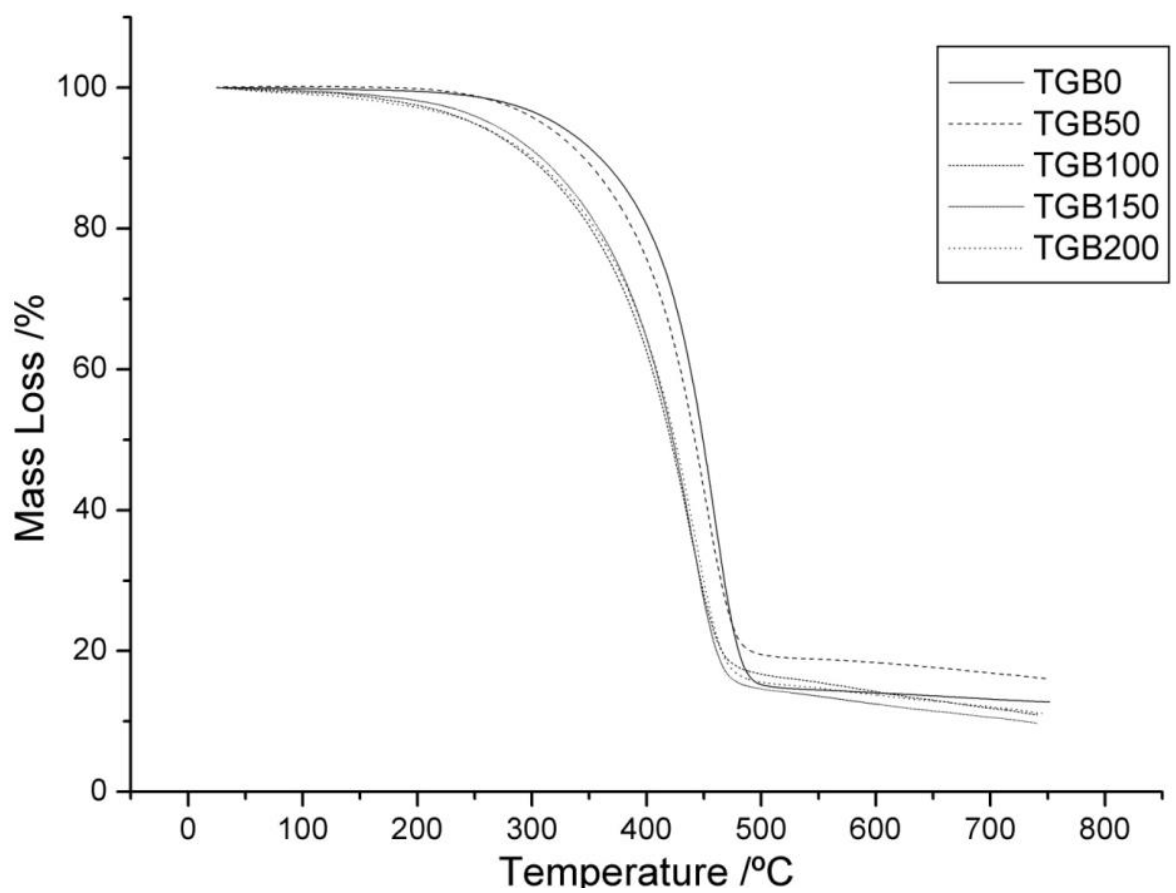

Figure 9. TG curves for conventional asphalt binder (B) before aging process (B 0 ) and after 50, 100, 150, and 200 hours of exposure in the weathering chamber.

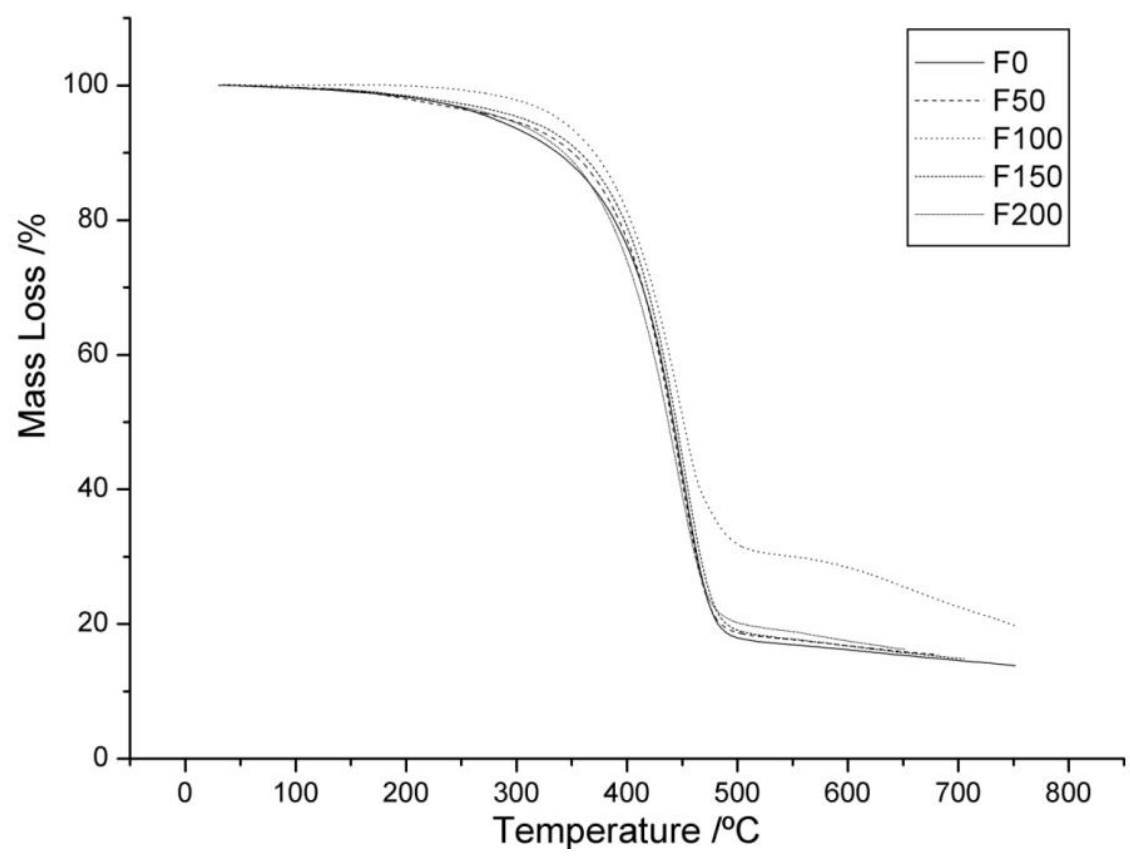

Figure 10. TG curves for polymer asphalt binder (F) before aging process (F 0 ) and after 50, 100, 150, and 200 hours of exposure in the weathering chamber. 
without aging. With aging, a break of double bonds and cross linking occurred, increasing thermal stability. The lowest thermal stability for the polymer binder was observed for the sample without aging by using TG analysis.

For the conventional asphalt binder, DTG curves obtained for samples after 100 and 200 hours of aging showed a slower process of mass loss, which could be due to the higher degree of cross linking. TG curves showed the highest thermal stability for the sample aged for 100 hours. The oxygen trapped in the oxidized structures aged for 100, 150, and 200 hours, reacted with carbon atoms, promoting cross linking in molecular structure.

\section{CONCLUSIONS}

At low frequencies (from $10^{-6}$ up $10^{2} \mathrm{rad}$ ), and for aging time up to 100 hours, the complex modulus of asphalt binders with and without polymer addition increased as the exposure time in the weathering chamber increased.

The complex modulus of polymer modified bitumen was higher than the complex modulus of conventional asphalt binder at low frequencies, before aging. For samples aged for 50h, SBS modified bitumen showed a lower complex modulus at low frequencies than the conventional asphalt binder. For samples aged for $100 \mathrm{~h}$, the SBS modified asphalt binder showed a higher complex modulus than the conventional asphalt binder at low frequencies, as expected. Despite these results, the benefit of polymer addition was minimized, and values of complex modulus of both binders were close.

At high frequencies, the addition of polymer in asphalt binders caused a slight decrease in the complex modulus. This behavior was observed for samples before aging process and after exposure time of 100 hours.

In the case of conventional asphalt cement, at low frequencies (from $10^{-6}$ up $10^{2} \mathrm{rad}$ ), the asphalt binders aged for $50 \mathrm{~h}$ and $100 \mathrm{~h}$ showed a higher complex modulus than the binder without aging, showing a better rutting resistance than the virgin binder.
For the asphalt cement and SBS modified bitumen samples, the aging process decreased the phase angle. As the aging time increased, the phase angle decreased.

All samples of conventional asphalt binder and SBS modified bitumen showed one decomposition stage of $85 \mathrm{wt} \%$ at $300^{\circ} \mathrm{C}$ related to the organic compounds.

The highest thermal stability for the asphalt binder without polymer addition was observed for the sample before aging. The thermal stability of bitumen decreased as the exposure time increased.

The samples aged for 100 hours showed the highest thermal stability among the polymer modified asphalt binder samples. A marked drop in thermal stability of aged samples was observed after 100 hours for the polymer modified bitumen and after 50 hours for the conventional bitumen.

\section{ACKNOWLEDGMENTS}

Authors would like to thank the governmental agencies Conselho Nacional de Desenvolvimento Científico e Tecnológico, CNPq; Coordenação de Aperfeiçoamento de Pessoal de Nível Superior, CAPES; Fundação de Amparo à Pesquisa do Estado de Minas Gerais, FAPEMIG; Departamento de Estradas de Rodagem de Minas Gerais; Centro de Pesquisa e Desenvolvimento Leopoldo Américo Miguez de Mello; and Laboratoire Central des Ponts et Chaussées (LCPC), in France, for supporting this research.

\section{REFERENCES}

Airey, G. D. Rheological properties of styrene butadiene styrene polymer modified road bitumens. Fuel, v. 82, p. 1709-1719, 2003. http://dx.doi.org/10.1016/S0016-2361(03)00146-7

Alvarez, A.E.; Ovalles, E.; Martin, A.E. Comparison of asphalt rubber-aggregate and polymer modified asphalt-aggregate systems in terms of surface free energy and energy indices. Construction \& Buildings Materials, v. 35, p.38592, 2012. http://dx.doi.org/10.1016/j.conbuildmat.2012.04.029 
Anderson, D.A.; Christensen, D.W.; Bahia, H.U.; Dongre, R.; Sharma, M.G.; Antle, C.E. Binder Characterization and Evaluation. Washington, DC: National Research Council; 1994.

Benbouzid, M.; Hafsi, S. Thermal and kinetic analyses of pure and oxidized bitumens. Fuel, v. 87, p.1585-90, 2008.

http://dx.doi.org/10.1016/i.fuel.2007.08.016

Bernier, A.; Zofka, A.; Yut, I. Laboratory evaluation of rutting susceptibility of polymermodified asphalt mixtures containing recycled pavements. Construction and Building Materials, v. 31, p. 58-66, 2012.

http://dx.doi.org/10.1016/j.conbuildmat.2011.12.094

Fernández-Gómez, W.D.; Quintana, H.A.R.; Daza, C.E.; Lizcano, F.A.R. The effects of environmental aging on Colombian asphalts. Fuel, v. 115, p. 321-328, 2014.

http://dx.doi.org/10.1016/i.fuel.2013.07.009

Ferry, J.D. Viscoelastic properties of polymers. $3^{\text {rd }}$. New York: Wiley \& Sons; 1980.

Giuliani, F.; Merusi, F.; Filippi, S.; Biondi, D.; Finocchiaro, M.L.; Polacco, G. Effects of polymer modification on the fuel resistance of asphalt binders. Fuel, v. 88, p.1539-1546, 2009. http://dx.doi.org/10.1016/j.fuel.2008.12.023

Guedes R.M. A viscoelastic model for a biomedical ultra-high molecular weight polyethylene using the time-temperature superposition principle. Polymer Testing, v.30, p.294-302, 2011.

http://dx.doi.org/10.1016/i.polymertesting.2011.01.006

Iskender, E.; Aksoy, A.; Ozen, H. Indirect performance comparison for styrene-butadienestyrene polymer and fatty amine anti-strip modified asphalt mixtures. Construction \& Buildings Materials, v. 30, p.117-124, 2012. http://dx.doi.org/10.1016/i.conbuildmat.2011.11.027

Leite L.F.M.; Martins, A.; Cravo, M. in Proc. of 50 Congreso Venezolano del asfalto, Isla Margarita, 2010.

Lesueur, D. The colloidal structure of bitumen: consequences on the rheology and on the mechanisms of bitumen modification. Advances in Colloid and Interface Science, v.145, p.42-82, 2009. http://dx.doi.org/10.1016/j.cis.2008.08.011
Lins, V.F.C.; Araújo, M.F.A.S.; Yoshida, M.I.; Ferraz, V.P.; Andrada, D.M.; Lameiras, F.S. Photodegradation of hot-mix asphalt. Fuel, v. 87, p. 3254-61, 2008.

http://dx.doi.org/10.1016/i.fuel.2008.04.039

Liu, G.; Leegwater, G.; Nielsen, E.; Komacka, J.; van de Ven, $M$. Evaluating the rheological properties of PMB-containing RA binders from surface-layer asphalt mixtures to be recycled. Construction and Building Materials, v. 49, p. 814, 2013.

http://dx.doi.org/10.1016/j.conbuildmat.2013.08.012

Lo Presti, D. Recycled Tyre Rubber Modified Bitumens for road asphalt mixtures: A literature review. Construction and Building Materials, v. 49, p. 863-881, 2013.

http://dx.doi.org/10.1016/j.conbuildmat.2013.09.007

Mastrofini, D.; Scarsella, M. The application of rheology to the evaluation of bitumen ageing. Fuel, v.79, p.1005-15, 2000.

http://dx.doi.org/10.1016/s0016-2361(99)00244-6

Modarres, A. Investigating the toughness and fatigue behavior of conventional and SBS modified asphalt mixes. Construction and Building Materials, v. 47, p. 218-222, 2013.

http://dx.doi.org/10.1016/i.conbuildmat.2013.05.044

Mouillet, V.; Lamontagne, J.; Durrieu, F.; Planche, J.P.; Lapalu, L. Infrared microscopy investigation of oxidation and phase evolution in bitumen modified with polymers. Fuel, v.87, p. 1270-80, 2008a.

http://dx.doi.org/10.1016/i.fuel.2007.06.029

Mouillet, V.; Farcas,F.; Besson, S. Ageing by UV radiation of an elastomer modified bitumen. Fuel, v.87, p. 2408-2419, 2008b.

http://dx.doi.org/10.1016/i.fuel.2008.02.008

Pérez-Lepe, A.; Martínez-Boza, F.J.; Gallegos, C.; González, O.; Muñoz, M.E.; Santamaría, A. Influence of the processing conditions on the rheological behaviour of polymer-modified bitumen. Fuel, v.82, p.1339-48, 2003. http://dx.doi.org/10.1016/S0016-2361(03)00065-6

Polacco, G.; Stastna, J.; Biondi, D.; Antonelli, F.; Vlachovicova, Z.; Zanzotto, L. Rheology of asphalts modified with glycidylmethacrylate functionalized polymers. Journal of Colloid and Interface Science, v. 280 , p. 366-373, 2004. http://dx.doi.org/10.1016/j.jcis.2004.08.043 
Polacco, G.; Stastna, J.; Biondi, D.; Zanzotto, L. Relation between polymer architecture and nonlinear viscoelastic behavior of modified asphalts. Current Opinion in Colloid and Interface Science, v. 11, p.230-45, 2006.

http://dx.doi.org/10.1016/i.cocis.2006.09.001

Rebelo, L.M.; Sousa, J.S.; Abreu, A.S.; Baroni, M.P.M.A.; Alencar, A.E.V.; Soares, S.A., Mendes Filho, J.; Soares, J.B. Aging of asphaltic binders investigated with atomic force microscopy. Fuel, v. 117, p. 15-25, 2014.

http://dx.doi.org/10.1016/j.fuel.2013.09.018

Rekha, A.P.; Krishnan, J.M.; Experimental investigations on high temperature transition of asphalt. Construction and Building Materials, v. 25, p. 4221-4231, 2011.

http://dx.doi.org/10.1016/j.conbuildmat.2011.04.064

Ruan, Y.; Davison, R.R.; Glover, C.J. The effect of long-term oxidation on the rheological properties of polymer modified asphalts. Fuel, v. 82, p. 176373, 2003.

http://dx.doi.org/10.1016/S0016-2361(03)00144-3

Saal, R.N.J. Physical Properties of Asphaltic Bitumen. I. Rheological Properties, The Properties of Asphaltic Bitumen. New York: Elsevier Publishing Company; 1950.

Sengul, C.E.; Oruc, S.; Iskender, E.; Aksoy, A. Evaluation of SBS modified stone mastic asphalt pavement performance. Construction and Building Materials, v. 41, p. 777-783, 2013.

http://dx.doi.org/10.1016/i.conbuildmat.2012.12.065
Sugano, M.; Kajita, J.; Ochia,i M.; Takagi, N.; Iwai, S.; Hirano, K. Mechanisms for chemical reactivity of two kinds of polymer modified asphalts during thermal degradation. Chemical Engineering Journal, v. 176-177, p. 231-6, 2011. http://dx.doi.org/10.1016/i.cej.2011.08.080

Tabatabaee, H.A; Velasquez, R.; Bahia, H.U. Predicting low temperature physical hardening in asphalt binders. Construction \& Buildings Materials, v. 34, p. 162-9, 2012.

http://dx.doi.org/10.1016/j.conbuildmat.2012.02.039

Topal, A. Evaluation of the properties and microstructure of plastomeric polymer modified bitumens. Fuel Processing Technology, v. 91, p. 4551, 2010.

http://dx.doi.org/10.1016/i.fuproc.2009.08.007

Yildirim, Y. Polymer modified asphalt binders. Construction \& Buildings Materials, v. 21, p.66-72, 2007.

http://dx.doi.org/10.1016/j.conbuildmat.2005.07.007

Zhang, F.; Hu, C. The research for SBS and SBR compound modified asphalts with polyphosphoric acid and sulfur. Construction and Building Materials, v. 43, p. 461-468, 2013.

http://dx.doi.org/10.1016/i.conbuildmat.2013.03.001 